\title{
Indeterminateness in industrial and organisational psychological research: A root metaphor analysis
}

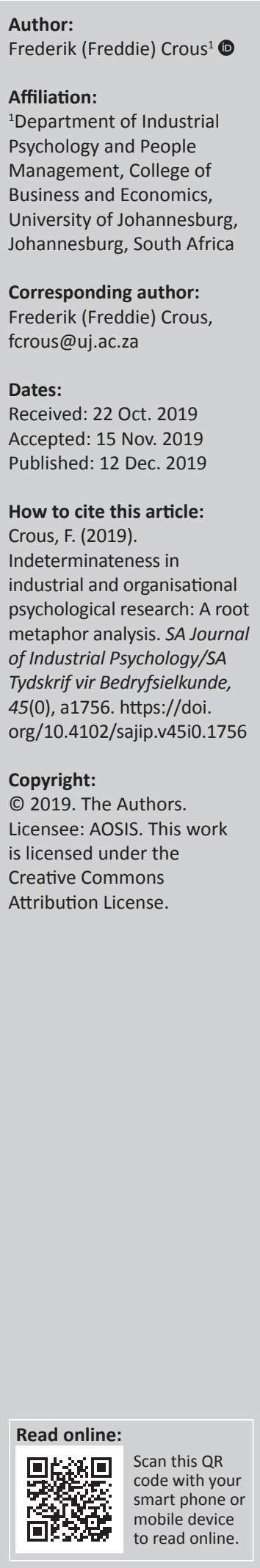

Problematisation: Efendic and Van Zyl (2019) attribute the so-called replication crisis in psychological research and industrial and organisational (I/O) psychological research in particular to a series of systemic issues. Be that as it may, their opinion does not consider the worldview/world hypothesis/world theory/paradigm with its distinct, underlying logic/ cognitive pathway and root metaphor in which the replication crisis is embedded.

Implications: By considering the worldview in which they operate, researchers and practitioners may come to understand the basis of the reproducibility and replicability challenge in psychological research. By ignoring it, those researchers and practitioners may become increasingly frustrated with their research efforts. By understanding it, they should appreciate and value Efendic and Van Zyl's (2019) recommended strategies.

Purpose: The purpose of this rebuttal in the form of an opinion paper is not to provide an opposing argument or dispute but rather to offer an extension to, or refinement of, these authors' opinion. This effort is initiated by the following question: what is the problem of indeterminateness (suggested by the replication crisis), which is endemic to the dominant $\mathrm{I} / \mathrm{O}$ psychological research paradigm? By going beyond the systemic issues identified by Efendic and Van Zyl, this problem is addressed on a worldview level.

Recommendation: In view of the evidence provided, it is concluded that - contrary to belief - psychologists employ a formistic, rather than a mechanistic, root metaphor or logic. As imprecision is an inherent weakness of formism, psychologists who research and practise from this worldview have no choice but to adhere to the recommendations or strategies proposed by Efendic and Van Zyl. In doing so, however, they will not be able to completely do away with the problem of indeterminateness in I/O psychology, but these authors' recommended strategies will provide them with the means for dealing with this weakness inherent in their research paradigm in a responsible manner

Keywords: precision/imprecision; world hypothesis; cognitive pathway; root metaphor; formism; replication crisis; industrial and organisational (I/O) psychology.

\section{Introduction}

Although not explicitly expressed by Efendic and Van Zyl (2019), the authors seem to imply that what underlies the predictability and reproducibility challenge - the so-called replication crisis - in psychological research in general, and in industrial and organisational (I/O) psychological research in particular, is a lack of precision. This predicament begs the question, 'why is the problem of indeterminateness endemic to the dominant I/O psychological research paradigm?' In order to address this question, I propose that one needs to go beyond the systemic issues identified by Efendic and Van Zyl (2019) and deal with this challenge or crisis on a worldview level. The purpose of this article is therefore not to provide an opposing argument or dispute but rather to offer an extension to, or refinement of, Efendic and Van Zyl's (2019) opinion.

To explore the nature of the lack of precision or accuracy in I/O psychological research on a worldview level, I will use the systematic philosopher Pepper's (1942) root metaphor method. This method suggests four cognitive pathways to knowledge, each with a distinctive kind of logic and unique strengths and weaknesses. The objective of this article is therefore to ascertain which pathway (logic) I/O psychologists predominantly employ, the challenge this approach poses for the precision of their research and to what extent Efendic and Van Zyl's (2019) recommended strategies for addressing reproducibility and replicability can ameliorate the problem of indeterminateness in I/O psychology. 
Next, I will provide an overview of root metaphor theory and then argue why psychologists - contrary to belief predominantly use a formistic cognitive pathway, rather than a mechanistic one. In order to have an understanding of the indeterminate nature of formism, an example of how psychologists go about studying a particular type of behaviour, namely, entrepreneurial behaviour, is provided. This effort is meant to explore the nature and extensiveness of formistic logic, not to detract from Efendic and Van Zyl's (2019) opinion; the article finally concludes that adopting the open science practices and methodological improvements suggested by Efendic and Van Zyl (2019) should ameliorate the weakness of imprecision inherent in formism.

\section{Root metaphor theory}

Pepper (1942) asserted that an understanding of the nature of the world is made possible by the basic cognitive process of metaphorical thinking - a claim corroborated almost 40 years later by Lakoff and Johnson (1980) in their work Metaphors We Live by. That book focusses on conceptual metaphors, in what is nowadays referred to as conceptual metaphor theory (CMT) (Landau, Robinson, \& Meier, 2014). Metaphors are particularly effective because they act to make 'something that is familiar [...] represent something that is unfamiliar, something that is concrete [...] represent something that is abstract, something understood [represent] something that is not' (Tversky, 2019, p. 118). A metaphor therefore serves as a heuristic tool (Gillespie, 1992) that can be cognitively utilised to make sense of the world. The use of metaphor is so deeply ingrained as a cognitive mechanism influencing how we humans think, feel and behave (Landau et al., 2014) that we are not conscious of its effect on our lives (Ackerman, Nocera, \& Bargh, 2010; Lakoff \& Johnson, 1999).

Various metaphors are available for creating hypotheses about the world and its workings, but not all of them are valid. In fact, most of them are found wanting (Payne, 1996). For this reason, Pepper (1942) embarked on a systematic analysis of the discipline of philosophy's most adequate ideas or systems. He found that those can be subsumed into four clusters, each with its own underlying root metaphor, thereby suggesting four relatively adequate hypotheses about the structuring of the world which are universally valid (Payne, 1996). The criteria Pepper (1942) used to validate their adequacy are precision and scope. Each of the four dominant world hypotheses includes a particular worldview or world theory, similar to Kuhn's (1962) idea of a paradigm. Pepper (1942) defined these as formism, mechanism, organicism and contextualism. The root metaphor of formism is similarity (of type), mechanism pertains to the machine or the mechanical, organicism refers to the living organisation and contextualism refers to historic events.

Pepper (1942) suggested that scientists, researchers and scholars employ these root metaphors as cognitive pathways to structure their endeavours aimed at the refinement of knowledge. According to Ackerman et al. (2010) and Lakoff and Johnson (1999), such an undertaking seldom unfolds on

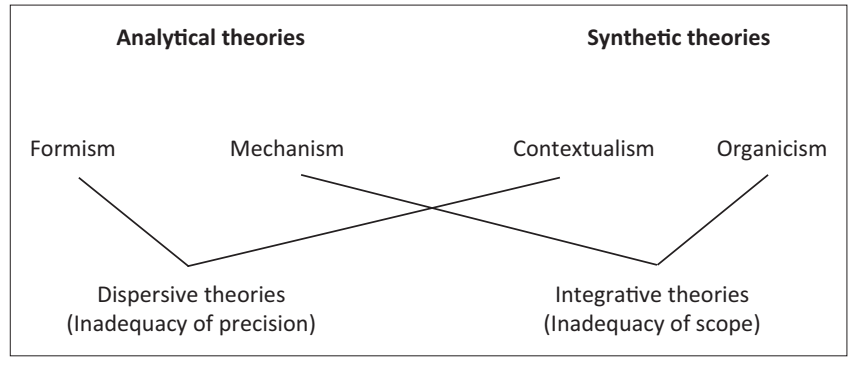

Source: Pepper (1942, p. 146)

FIGURE 1: A schematic summary of world hypotheses.

a conscious level. Root metaphor theory suggests that world hypotheses, views or theories are autonomous and, as such, mutually exclusive, suggesting 'a mixture of them ... can only be confusing' (Pepper, 1942, p. 104).

Pepper (1942) came to realise that these four world hypotheses arrange themselves in two groups: formism and mechanism are analytical, while organicism and contextualism are synthetic. The second polarity between the pairings sees formism and contextualism being described as dispersive, while mechanism and organicism are deemed to be integrative, exposing either inadequacy in terms of precision or of scope. Figure 1 presents a schematic, symmetrical summary of Pepper's (1942) view of the two sets of polarities.

Given their dispersive nature, formism and contextualism are appropriate for open systems. By contrast, mechanism and organicism - because of their integrative nature - are appropriate for closed systems (Capaldi \& Proctor, 1999).

Pepper (1942) suggested that psychological research falls within the analytical realm of mechanism, with its root metaphor of the machine: ' $[i] \mathrm{t}$ may be a machine like a watch or a machine like a dynamo' (p. 186), or the machine-like biological structure of the body, such as the heart, which operates according to mechanical principles (Proctor \& Capaldi, 2006). Machines consist of elements, each of which can be isolated and subsequently examined. It is the functional connections that reveal the workings of machines (Super \& Harkness, 2003), and it is the cognitive pathway of mechanism that ensures precision and accuracy. Winchester (2018), for instance, observed that the scientific and industrial revolutions each owed their success to a single engineering element, namely, precision.

Thus, what kind of psychology can be described as being mechanistic in nature? According to Pepper (1942), it was a psychology of:

$[D]$ iscrete mental elements of a relatively small number of kinds: sensations of color, sound, taste, smell, various sorts of tactile sensations, feelings such as pleasantness and unpleasantness. This sort of psychology is sometimes dubbed 'mental

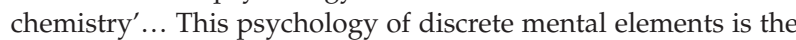
neatest and ... the most intellectually satisfying psychology that has been developed. (pp. 218-219)

This kind of psychology, admired by Pepper (1942), can be traced back to the early experimental psychology of E.B. Titchener, the English-American psychologist, which 
ultimately led to the kind of research conducted in the domain of cognitive neuropsychology (see Alexander \& Shelton, 2014).

This is not, however, the kind of research that finds its way into the SA Journal of Industrial Psychology or similar journals. If the majority of $\mathrm{I} / \mathrm{O}$ psychologists do not use the mechanistic cognitive pathway, which cognitive pathway does in fact underlie the dominant research in this field? I would argue that I/O psychologists approach their research from a formistic perspective. Formism is analytical in nature, and it is the kind of $\mathrm{I} / \mathrm{O}$ psychological research which Efendic and Van Zyl (2019) refer to, for which quantitative or statistical methods are applied for analytical purposes. Formism is, however, characterised as dispersive (see Figure 1), and as such its weakness is its inadequacy in precision or accuracy, which means that it is handicapped by an inherent indeterminateness.

\section{Formism: The industrial and organisational psychologist's cognitive pathway to knowledge}

In this section, I will provide a basic example to describe the formistic way in which I/O psychologists study a particular type of behaviour, namely, entrepreneurial behaviour (i.e. entrepreneurship). (It is not unusual for psychologists to study entrepreneurship - see Gielnik, Bledlow and Stark [2019] and Johnson, Madole and Freeman [2018].)

The root metaphor of formism is similarity (of type). Pepper (1942) identified the following common-sense perceptions as examples of similar things:

The world is full of things that seem to be just alike: blades of grass, leaves of a tree, a set of spoons, newspapers under a seller's arm, the sheet of a simple ream of paper. (p. 151)

In what way are entrepreneurs alike? To answer this question, the researcher can apply the following simple formistic formula:

$Y=f\left(X_{1}, X_{2}, X_{3}, \ldots, X_{n}\right)$

where $Y$ represents the criterion variable (which the industrial psychological researcher wants to predict - in this case entrepreneurship); $f$ represents the phrase 'function of' (which implies causality) and Xs represent the various predictor variables, such as the various attributes of an entrepreneur.

This formula suggests that the I/O psychological researcher primarily seeks to understand and predict entrepreneurial behaviour by means of free-standing variables in the form of attributes (such as personality traits). This formistic approach is associated with an Aristotelian way of thinking (Lewin, 1951; Pepper, 1942), which dominates the field of industrial psychology (Argyris, 1976). This means that industrial psychological researchers primarily focus on the attributes 'in' people (independent variables) in order to predict a particular behaviour, such as entrepreneurship (the dependent variable).

Few entrepreneurs manage to make their enterprises sustainable or to scale up their businesses (Cook, 2019). That is probably why I/O psychologists who study successful entrepreneurial behaviour tend to hone in on overtly positive psychological attributes, which they deem to be determinants of entrepreneurial success, such as self-efficiency, risk propensity, creativity, innovativeness, a growth orientation, an internal locus of control, ambition, a high need for achievement, self-directedness, interpersonal skill, energy, being focussed, etc. This development has prompted the guru of all management gurus, Drucker (1985), to lament that the personological approach to entrepreneurship has made caricatures of entrepreneurs, most probably because of a misplaced attention on the extreme and a neglect of the mundaneness in the study of entrepreneurship (Aldrich \& Ruef, 2018) and ignoring the entrepreneur's social identity (Wry \& York, 2019). The advent of the positive psychology movement, with its offshoots such as positive organisational scholarship (POS) and positive organisational behaviour (POB), provides the I/O psychologists who are studying entrepreneurship with an opportunity to add substantially to the list of positive attributes affecting entrepreneurial behaviour.

In opposing such positive profiles of entrepreneurs, the management scholar and psychoanalyst Kets de Vries (1985, 1989) and Spivack and McKelvie (2018) emphasise unfavourable factors in the entrepreneur's background and point to the dark side of the entrepreneurial personality. Having to take into account this contradiction serves to compromise our understanding of entrepreneurial behaviour even more. Not only I/O psychologists but also other researchers (including those in the social and business sciences) have added to the long list of variables in attempting to profile 'the entrepreneur'. This continuous extension of predictor variables, including possible moderators and mediators, represents the biggest challenge posed by formism: the more information regarding a 'fact' becomes available, the more difficult it becomes to adequately understand such a fact (Pepper, 1942). The strength of formism, namely, adequate scope, therefore undermines its precision or accuracy. Given the wide scope that formism provides, no two I/O psychological researchers who utilise this particular cognitive pathway are able to define, operationalise or measure the criterion and predictor variables in the exact same way. And, of course, psychological constructs cannot be measured directly - that undertaking is reserved for mechanism.

The formistic root metaphor of similarity aligns with 'difference' or 'otherness' (Pepper, 1942, p. 155). This is not foreign to the I/O psychologist because 'the study of individual differences is a major foundation of the field' (Argyris, 1976, p. 152). The I/O psychologist researching entrepreneurial behaviour, for example, not only aims to ascertain in what respects entrepreneurs are similar but also how entrepreneurs and non-entrepreneurs differ. 
This objective is not, however, easily attained. Referring back to the earlier related example, Nandram and Samsom (2007) point out that the value of many of those attributes that are identified as predictors of successful entrepreneurial behaviour can be questioned, having been found not to be unique to entrepreneurs. This has led a number of scholars to conclude that 'attempts to develop a ... profile of the typical entrepreneur have been largely unsuccessful' (p. 3). ${ }^{1}$

The I/O psychology practitioner is faced with the same formistic challenges as the industrial psychology researcher. Payne (1996) seeks to clarify this with a biologyrelated analogy:

[W] here it would be possible to make a good guess at the kind of animal or plant that might survive given ecological circumstances. In industry and commerce personnel selection attempts this very problem using a formistic root metaphor by drawing up job and person specifications and trying to find the person who best fits the categories. Some of the reasons why selection systems are less successful than was once hoped are that taxonomies of jobs, people and performance criteria are inadequately developed and somewhat unreliable in use. (p. 186)

Pepper (1942) argued that because of formism's lack of precision, it appears to be the most inadequate of the four 'favoured ones' (the other three being mechanism, organicism and contextualism). Pepper (1942, p. 144) was nonetheless reluctant to discard formism because 'of the very strong feeling of certainty which attaches to its root metaphor, namely, the intuition of similarity', but strongly advised that formism's indeterminateness needs to be 'bolstered up'.

\section{Conclusion}

Because I/O psychologists deem measurement to be central to their research and practices, they wrongly consider their work to be mechanistic in nature. By means of an illustration of how I/O psychologists study a particular type of behaviour, namely, entrepreneurial behaviour, I have tried to show that their kind of logic is formistic in nature. However, the fundamental weakness of formism is imprecision. How then should I/O psychologists go about improving their research practices and methods, given that the research paradigm of formism (in which their research is embedded) is ironically antithetical to precision? Payne (1996) suggests that reliability, construct validity and adequate sampling are the more important criteria of formism, which have to be strengthened. Efendic and Van Zyl (2019) are much more specific in this regard: their detailed and actionable arguments and recommendations for open science practices and methodological improvements should ameliorate the weakness of formism. In doing so, it

1.Bateman and Porath (2003) point to Lewin's (1951) view (which is embedded in Aristotelian [and therefore formistic] logic that, in order to understand a particular behaviour, not only factors within the pic th but also outside of him or harticular behaviour, not only factors within the person but also outside of him or her, such 'indefinitens' 'indefiniteness' of formism (cf. Pepper 1942), as it may include not only the external constraints which entrepreneurs are subjected to but also the resources required to nourish their entrepreneurial endeavours. (Manolova, Edelman, Shirokova \& Tsukanova, 2019). will counter the inadequacy of the dominant I/O psychological research paradigm, which is its lack of precision or accuracy and subsequent indeterminateness. The responsible approach to be taken by authors and journal editors who are active in the dominant formistic research paradigm is to take note of and apply Efendic and Van Zyl's (2019) proposed best course of action to enhance the credibility of I/O psychological research, even though it may prove impossible to succeed completely in overcoming its inherent lack of precision.

\section{Acknowledgements Competing interests}

The author declares that he has no financial or personal relationships which may have inappropriately influenced him in writing this article.

\section{Author's contributions}

F.C. is the sole author of this research article.

\section{Ethical considerations}

This article followed all ethical standards for a research without direct contact with human or animal subjects.

\section{Funding information}

This research was funded by the Department of Industrial Psychology and People Management, College of Business and Economics, University of Johannesburg.

\section{Data availability statement}

Data sharing is not applicable to this article as no new data were created or analysed in this study.

\section{Disclaimer}

The views and opinions expressed in this article are those of the author and do not necessarily reflect the official policy or position of any affiliated agency of the author.

\section{References}

Ackerman, J.B., Nocera, C.C., \& Bargh, J.A. (2010). Incidental haptic sensations influence social judgments and sensations. Science, 328(5986), 1712-1715. https://doi.org/10.1126/science.1189993

Aldrich, H.E., \& Ruef, M. (2018). Unicorns, gazelles, and other distractions on the way to understanding real entrepreneurship in the United States. Academy of Management Perspectives, 32(4), 458-472. https://doi.org/10.5465/amp 2017.0123

Alexander, B.K., \& Shelton, C.P. (2014). A history of psychology in Western civilization. Cambridge: Cambridge University Press.

Argyris, C. (1976). Problems and new directions for industrial psychology. In M.D. Dunnette (Ed.), Handbook of industrial and organizational psychology, (pp. 151-184). Chicago, IL: Rand McNally.

Bateman, J.S., \& Porath, C. (2003). Transcendent behavior. In K.S. Cameron, J.E Dutton, \& R.E. Quinn (Eds.), Positive organizational scholarship, (pp. 122-137). San Francisco, CA: Berrett-Koehler.

Capaldi, E.J., \& Proctor, R.W. (1999). Contextualism in psychological research? A critical review. London: Sage.

Cook, J. (2019, October 8). Entrepreneurship: How small firms leave the playground. Business Day, p. 7 
Drucker, P.F. (1985). Innovation and entrepreneurship: Practice and principles. London: Heineman.

Efendic, E., \& Van Zyl, L.E. (2019). On reproducibility and replicability: Arguing for open science practices and methodological improvements at the South African Journa of Industrial Psychology. SA Journal of Industrial Psychology/SA Tydskrif vir Bedryfsielkunde, 45, a1607. https://doi.org/10.4102/sajip.v45i0.1607

Gielnik, M.M., Bledow, R., \& Stark, M.S. (2019). A dynamic account of self-efficacy in entrepreneurship. Journal of Applied Psychology. https://doi.org/10.1037/ apl0000451

Gillespie, D. (1992). The mind's we: Contextualism in cognitive psychology. Carbondale, IL: Southern Illinois University Press.

Johnson, S.L., Madole, J.W., \& Freeman, M.A. (2018). Mania risk and entrepreneurship: Overlapping personality traits. Academy of Management Perspectives, 32(2), 207-227. https://doi.org/10.5465/amp.2016.0165

Kets de Vries, M.F.R. (1985). The dark side of entrepreneurship. Harvard Business Review, 36(6), 160-167.

Kets de Vries, M.F.R. (1989). Prisoners of leadership. New York: Wiley.

Kuhn, T.S. (1962). The structure of scientific revolutions. Chicago, IL: University of Chicago Press.

Lakoff, G., \& Johnson, M. (1980). Metaphors we live by. Chicago, IL: University of Chicago Press.

Lakoff, G., \& Johnson, M. (1999). Philosophy in the flesh: The embodied mind and its challenge to western thought. New York: Basic Books.

Landau, M.J., Robinson, M.D., \& Meier, B.P. (2014). The power of metaphor: Examining its influence on social life. Washington, DC: American Psychological Association.

Lewin, K. (1951). Field theory in social science. New York: Harper.
Manolova, T.S., Edelman, L.F., Shirokovac, G., \& Tsukanovac, T. (2019). Youth entrepreneurship in emerging economies: Can family support help navigate institutional voids? Journal of East-West Business, 25(4), 363-395. https://doi. org/10.1080/10669868.2019.1624672

Nandram, S., \& Samsom, K. (2007). Entrepreneurial behaviour: New perspectives gained through the critical incident technique. Nyenrode Research Group Working Paper Series, 07. Breukelen: Nyenrode Research Group, Nyenrode Business University.

Payne, R.L. (1996). Contextualism in context. International Review of Industrial and Organisational Psychology, 11, 181-218.

Pepper, S.C. (1942). World hypotheses: A study in evidence. Los Angeles, CA: University of California Press.

Proctor, R.W., \& Capaldi, E.J. (2006). Why science matters: Understanding the methods of psychological research. Oxford: Blackwell.

Spivack, A.J., \& Mckelvie, A. (2018). Entrepreneurship addiction: Shedding light on the manifestation of the 'dark side' in work-behavior patterns. Academy of Management Perspectives, 32(3), 358-378. https://doi.org/10.5465/amp.2016. 0185

Super, C.M., \& Harkness, S. (2003). The metaphors of development. Human Development, 46, 3-23. https://doi.org/10.1159/000067782

Tversky, B. (2019). Mind in motion: How action shapes thought. New York: Basic Books.

Winchester, S. (2018). The perfectioners: How precision engineers created the modern world. New York: Harper Collins.

Wry, T., \& York, J.G. (2019). Blended colors or black and white? Avoiding dichotomous thinking in identity and entrepreneurship. Academy of Management Review, 44(1), 215-219. https://doi.org/10.5465/amr.2018.0111 